\title{
UP School: Motion, Perception, Learning
}

\author{
Lino Cabras and Fabrizio Pusceddu
}

\begin{abstract}
The design strategy common to the educational spaces for the "Up School" based in the metropolitan area of Cagliari aims to frame a flexible learning space open to experimentation and the active exploration of places. Indeed, learning does not merely mean collecting and memorizing information; it also requires the ability to select, connect, understand and integrate, first by acquiring self-awareness and by developing perceptual abilities. Space-as experienced in its dynamic dimensionplays a crucial role in this process. The principles of the dynamic perception of space established by the most important investigations in neuroscience of recent years, were declared by the experimentations of the Bauhaus workshops, ahead of their time, as being strongly related to space, body and mind. Beginning with this premise, the "Up School" project—nursery, preschool and primary schoolintegrates an innovative educational program with the spatial layout of its environments. These spaces are conceived as a fluid sequence of "affordances" where, from an early age, children can shape their world within a perspective guided by good sustainability practices, enabling technologies and psychomotor equilibrium. Thus, the school system changes by being more conscious of its fulcrum: namely, the psychosomatic dimension of the individual.
\end{abstract}

Keywords Exploration $\cdot$ Active perception $\cdot$ Sharing $\cdot$ Dynamism $\cdot$ Community $\cdot$ Flexible spaces

The very etymology of the word knowledge contains an active meaning, which links the concept of testing reality with our need for choices, decisions and having awareness of the world we live in.

\footnotetext{
L. Cabras $(\bowtie) \cdot$ F. Pusceddu

Department of Architecture, Design and Urban Planning, University of Sassari, Sassari, Italy e-mail: 1cabras@uniss.it

F. Pusceddu

e-mail: fapusceddu@uniss.it
} 
Whether it is the Italian conoscere (from the Latin cognoscere cf. "recognize", "gnosis") or the English "knowledge" ("gnosis"), and whether it is voluntary or involuntary, knowledge is the result of an action.

Awareness is the factor that explains reality as a complex entity with which we interact by establishing relationships between physical objects and mental objects. Thus the experiential condition becomes the foundation for understanding the world and recognizing how reality is strongly affected by the way we describe, observe, and perceive it sometimes subjectively, sometimes collectively.

Knowledge is no longer a cognitive concept, but it is directly linked to the need for action. In order to act we need knowledge, but the only way we can have access to knowledge is by acting. According to Berthoz, the reason for this process is the intrinsic need of human beings to correlate the perceptive component with the motor component, that is, "perceiving something as a function of" and "making something as a function of". The brain is the core of these operations and it acts as a convergence tool between the two above-mentioned components, and also as an information processing center and action simulator [1]. Even learning activities in school environments are based on the same mechanism: the body is conceived as the essential component in relations with the immediate surroundings and with other individuals; motion is no longer considered a distracting element, but it has become the part of a process that we know to be intrinsic to our cognitive system. The most recent research in neuroscience appears to demonstrate a correlation between motor patterns and superior cognitive functions. Action is no longer understood to be a consequence of a perceptual phase - with a consequent interpretation - but rather constitutes the essential part of the process where all the components work simultaneously. This process is not structured in clearly distinguishable phases, but rather in the actual, or simulated, accomplishment of "motor actions" in which behavior is not seen as "mere movements" [2]. As a driver of processes and actions, space plays a revealing role in its surroundings and spontaneously suggests how they should evolve in the future. From this point of view, it is evident that spatial control and its design are foundational to the way human beings live, not only in terms of the functional need of shelter, protection, and comfort, but rather as a new structure of shapes and possible ways of inhabiting.

Today, we are keenly aware of the importance of the architecture of learning spaces, which should enhance sharing and cooperation processes, and the psychophysical well-being of individuals.

Pedagogical research confirms the need for architecture that is not conceived merely as closed off areas that are dedicated to specific settings—schools-but as spaces that can generate closer ties with the surrounding world, and that are modelled on complex interactions.

One hundred years after the founding of the Bauhaus, its educational principles have been largely confirmed by contemporary neuroscientific investigations, showing the similarity with the most contemporary learning theories. Thus, according to the program of the Staatliche Bauhaus Weimar described by founder Walter Gropius, laboratory practice determines a synesthetic experience within a social and didactic 
community. The aim of the school was to educate the natural abilities of individuals to understand the whole of existence, as a cosmic entity [3].

In the Bauhaus learning experience, it is even clearer that the study of form, color and space is the main tool for understanding reality. The pedagogical approach involves students starting a new learning process on a tabula rasa of their previous experiences. Johannes Itten, master of the Vorkurs - the school's preliminary course-was one of the teachers who applied a new radical learning method for art, aimed at reaching a new equilibrium. Itten's references took in the theories of Franz Cižek ${ }^{1}$ on the stimulation of creativity and Dewey's principles of Learning by doing, the foundations of the entire Bauhaus teaching program. The goal of his course was to train man as a creative being, invoking the synergy of the energy of the body, mind and spirit. ${ }^{2}$ Students' tactile skills were developed through specific exercises involving perception. ${ }^{3}$ A new dynamic equilibrium in which individuals can see another way of inhabiting and perceiving reality is sought in both two-dimensional and three-dimensional terms. Paul Klee' tool of investigation was perspective in motion, or the wandering viewpoint [5], where "man is not a species, but a cosmic point" [6]. For Oskar Schlemmer, on the other hand, who was appointed director of the school's theatre workshop in 1924, the laws between the human body and space were investigated through abstract choreographies. From a pedagogical point of view Schlemmer reminds us that theatre, in its fundamental component of abstract choreography, can be a precious tool for achieving self-awareness of the body [7]. The modernity of these concepts, which focus on the dynamic nature of reality can easily be found in the contemporary definition of space, where motion and sensorial experimentation are the fundament of the act of perception. ${ }^{4}$

With this in mind, the Up School design views architectural space as a continuum, where learning takes place through a dynamic perceptual experience aimed at guiding children towards autonomy.

The Up School of Cagliari has a preschool and a primary school located in the historic "Villino Campagnolo" building. The main unit is in the villa itself and there are two small accessory buildings, a former store and kitchens. The outdoor space includes a large monumental terraced garden where children can play, discover nature and grow vegetables. Both the mobile and the fixed components of the didactic space

\footnotetext{
${ }^{1}$ Founder of the Kunsterweberschule of Wien, an art school exclusively for children, where he developed a new teaching technique aimed at promoting the free expression of students, drawing inspiration from Maria Montessori's theories.

${ }^{2}$ Itten used a series of exercises taken from the Mazdaznan cult he had belonged to, an exoteric doctrine widespread in Europe in the early twentieth century, founded by Otto Hanisch.

${ }^{3}$ To perceive means to be moved, and to be moved means to form. [...] Without movementno perception, without perception—no form, without form stance. Substance-form. Form = movement in time and space; thus, substance $=$ movement in time and space 4.

${ }^{4}$ Space occurs as the effect produced by the operations that orient it, situate it, temporalize it, and make it function in a polyvalent unity of conflictual programs or contractual proximities [...] In short, space is a practiced place. Thus the street geometrically defined by urban planning is transformed into a space by walkers. In the same way, an act of reading is the space produced by the practice of a particular place: a written text, that is, a place constituted by a system of signs [8].
} 
provide multiple opportunities for children to interact during their daily activities. The furniture itself is designed and assembled to support children as they grow and to help them get the most out of making together and sharing knowledge. Thus, the conception of space is based on a radical re-assessment of action, enabling creative and active use. Inhabiting a space requires knowledge of how to interact with it, that is, knowledge is intrinsic to the space itself [9]. The pre-existing inner partitions of the villa were demolished to make way for flexible areas where groups of children of different ages can work and study in a shared space: classrooms were turned into learning environments and provided with functional and movable furniture designed for each different activity. Children learn in a "home" environment, made up of informal spaces, such as the reception and entertainment area for children, laboratories for experimental activities and water spaces for psycho-motor wellness. All the learning environments communicate with each other and overlook the large central hall-sharing space-which opens onto the terraced garden. The creativity room has a free, multifunctional configuration which depends on the activities taking place there. Paint stands and horizontal worktops are mobile and adaptable for plastic and manual arts. The fab lab space is the result of opening up four former rooms, whose original configuration can still be made out on the floor and in the way the walls are cut. The purpose is to facilitate flexible use of the space, as required by the multiplicity of the activities that take place in the fab lab: 3D printing, construction of small prototypes, coding classes and video/photo sets. The fab lab space is directly connected to the science laboratory and the augmented reality laboratory. The central space of the basement, which is directly linked to the terraced garden, features the "action area", dedicated to physical activity, relaxation and body awareness, and the water room, one of the central elements of Up School's educational program. Situated in the former utility spaces, the preschool is divided into two rooms by a movable, modular wooden wall, which can be opened when necessary. The wall also contains storage compartments and shutters connecting the two sections. A projector installed in the wooden roof generates an "interactive carpet" on the recycled vinyl floor, where children can go barefoot.

Similarly, the focus of the pedagogical program of the Up School preschool in Quartu Sant'Elena, namely, the development of basic motor skills in water, has spatial coordinates that are respectful of the pre-existing setting. Located in a traditional courtyard house, the preschool has a "water room" in the former storeroom, which has been redesigned as a glazed shell linked directly to the garden through a system of sliding doors, to achieve a continuous inside-outside space. The space contains three pools arranged in no particular layout and which the children use according to their age-related motor patterns. The different shapes are designed for specific needs: a rectangular pool, with a section increasing from 0 to $120 \mathrm{~cm}$, with variable water flows; a shallow geodetic pool that has different pressure levels; a water floor that is $10 \mathrm{~cm}$ deep, with a soft surface coated with different materials - smooth, uneven, rough - for tactile stimulation. A wooden walkway takes the children from the water space to the organic garden, where a system for collecting rainwater is connected to the house's ancient water tank, in turn a learning tool on nature's cycles and sustainability (Fig. 1). 


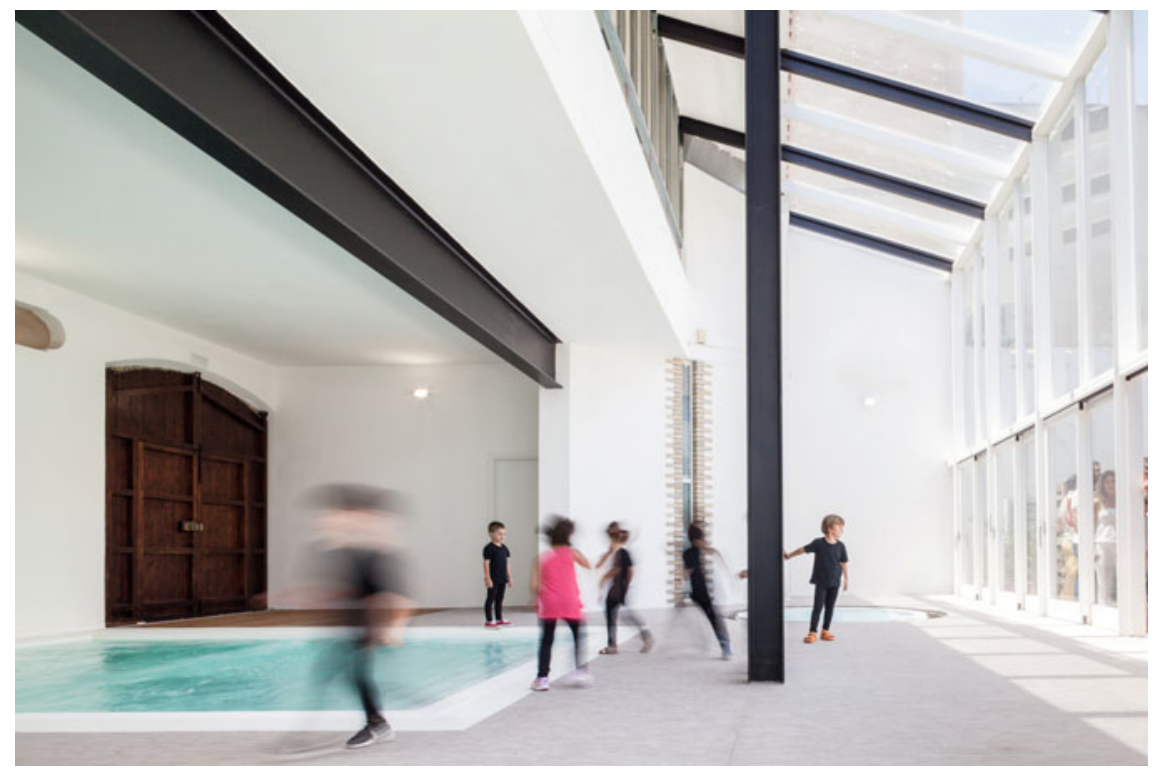

Fig. 1 The water room, Up School, Quartu Sant'Elena (photo@ Stefano Ferrando)

In conclusion, Tagliagambe's [10] definition of the Up School is as a place of balance: balance between the body and the mind, between awareness and emotions, knowledge and expertise, tradition and innovation, imagination and sense of reality. Balance for the education of full, complex individuals, who can live and work in contemporary society.

\section{References}

1. Berthoz, F.: Il senso del movimento. Mc Graw-Hill, Milan (1998)

2. Rizzolatti, G., Sinigaglia, C.: So quel che fai. Cortina, Milan (2006)

3. Gropius, W.: Il progrmma dello Staatlische Bauhaus. In Wingler, H.: Il Bauhuas. Weimar, Dessau, Berlino 1919-1933, Feltrinelli, Milan (1987)

4. Itten, J.: Analisi dei maestri del passato. In Wingler, H.: Op cit

5. Klee, P.: Quaderno di schizzi pedagogici. Abscondita, Milan (2002)

6. Klee, P.: Diari, 1898-1918. Il Saggiatore, Milan (2004)

7. Schlemmer, O.: "Akademie und Bühnestudio". In Bistolfi, M., ed.: Oskar Schlemmer Scritti sul teatro, Feltrinelli, Milan (1982)

8. Certeau (De), M.: L'invenzione del quotidiano, Edizioni Lavoro, Rome (2001)

9. Emery, N.: L'architettura difficile -filosofia del costruire-. Marinotti, Milan (2007)

10. Tagliagambe, S.: Idea di Scuola, Antonio Tombolini editore, Ancona, (2016). 
Open Access This chapter is licensed under the terms of the Creative Commons Attribution 4.0 International License (http://creativecommons.org/licenses/by/4.0/), which permits use, sharing, adaptation, distribution and reproduction in any medium or format, as long as you give appropriate credit to the original author(s) and the source, provide a link to the Creative Commons license and indicate if changes were made.

The images or other third party material in this chapter are included in the chapter's Creative Commons license, unless indicated otherwise in a credit line to the material. If material is not included in the chapter's Creative Commons license and your intended use is not permitted by statutory regulation or exceeds the permitted use, you will need to obtain permission directly from the copyright holder.

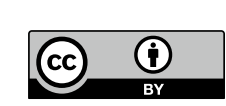

